\title{
Evidence-based Recommendations for the Management of Comorbidities in Rheumatoid Arthritis, Psoriasis, and Psoriatic Arthritis: Expert Opinion of the Canadian Dermatology-Rheumatology Comorbidity Initiative
}

\author{
Camille Roubille, Vincent Richer, Tara Starnino, Collette McCourt, Alexandra McFarlane, \\ Patrick Fleming, Stephanie Siu, John Kraft, Charles Lynde, Janet Pope, Wayne Gulliver, \\ Stephanie Keeling, Jan Dutz, Louis Bessette, Robert Bissonnette, and Boulos Haraoui
} ABSTRACT. Objective. Comorbidities such as cardiovascular diseases (CVD), cancer, osteoporosis, and depression
are often underrecognized in patients with rheumatoid arthritis (RA), psoriatic arthritis (PsA), or
psoriasis (PsO). Recommendations may improve identification and treatment of comorbidities. The
Canadian Dermatology-Rheumatology Comorbidity Initiative reviewed the literature to develop
practical evidence-based recommendations for management of comorbidities in patients with RA,
PsA, and PsO.

Methods. Eight main topics regarding comorbidities in RA, PsA, and PsO were developed. MEDLINE, EMBASE, and the Cochrane Library (1960-12/2012), together with abstracts from major rheumatology and dermatology congresses (2010-2012), were searched for relevant publications. Selected articles were analyzed and metaanalyses performed whenever possible. A meeting including rheumatologists, dermatologists, trainees/fellows, and invited experts was held to develop consensus-based recommendations using a Delphi process with prespecified cutoff agreement. Level of agreement was measured using a 10-point Likert scale $(1=$ no agreement, $10=$ full agreement $)$ and the potential effect of recommendations on daily clinical practice was considered. Grade of recommendation (ranging from A to D) was determined according to the Oxford Centre for Evidence-Based Medicine evidence levels.

Results. A total of 17,575 articles were identified, of which 407 were reviewed. Recommendations were synthesized into 19 final recommendations ranging mainly from grade $\mathrm{C}$ to $\mathrm{D}$, and relating to a large spectrum of comorbidities observed in clinical practice: CVD, obesity, osteoporosis, depression, infections, and cancer. Level of agreement ranged from $80.9 \%$ to $95.8 \%$.

Conclusion. These practical evidence-based recommendations can guide management of comorbidities in patients with RA, PsA, and PsO and optimize outcomes. (First Release July 15 2015; J Rheumatol 2015;42:1767-80; doi:10.3899/jrheum.141112)

Key Indexing Terms:

PSORIATIC ARTHRITIS RHEUMATOID ARTHRITIS COMORBIDITY PSORIASIS

From the University of Montreal Hospital Research Center (Centre de Recherche du CHUM), Notre-Dame Hospital; Department of Medicine, Dermatology Service, St-Luc Hospital; Sacré-Coeur Hospital of Montreal, University of Montreal; Innovaderm Research; Institut de Rhumatologie de Montréal, Montreal; Centre de Recherche du CHU de Québec, Department of Medicine, Laval University, Quebec City, Quebec; Department of Dermatology and Skin Science, University of British Columbia, Vancouver, British Columbia; Division of Rheumatology, University of Alberta, Edmonton, Alberta; Division of Dermatology, University of Toronto, Toronto; Division of Rheumatology, Western University of Canada, London; Lynde Dermatology, Markham, Ontario, Faculty of Medicine, Memorial University of Newfoundland, St. John's, Newfoundland, Canada.

AbbVie sponsored a meeting on the management of comorbidities, held in Toronto, Ontario, Canada, on May 31 to June 1, 2013. This publication summarizes the results of the Canadian Dermatology-Rheumatology (DR) Co-morbidity Initiative systematic literature searches (MEDLINE, EMBASE, Cochrane Library, 2010-2012 American College of

Rheumatology, European League Against Rheumatism, American Academy of Dermatology, European Academy of Dermatology and Venereology abstracts) and consensus-based recommendations from that meeting. AbbVie provided funding to Pinnacle Marketing and Education Inc. to manage the Canadian DR Co-morbidity Initiative that led to this paper. AbbVie paid consultancy fees to $B H, J P, L B, S K, R B, W G, J D, C L$, and $J K$ for their participation in the Canadian DR Co-morbidity Initiative. AbbVie paid Leading Edge for editorial support.

C. Roubille, MD, Rheumatology Research Fellow, University of Montreal Hospital Research Center (Centre de Recherche du CHUM), Notre-Dame Hospital; V. Richer, MD, Dermatology Resident, Department of Medicine, Dermatology Service, St-Luc Hospital; T. Starnino, MD, Rheumatology Resident, Sacré-Coeur Hospital of Montreal, University of Montreal; C. McCourt, MB, BCh, Clinical Fellow in Immunodermatology, Department of Dermatology and Skin Science, University of British Columbia; A. McFarlane, MD, Internal Medicine Resident, Division of Rheumatology, University of Alberta; P. Fleming, MD, Dermatology Resident, Division of Dermatology, University of Toronto; S. Siu, MD Internal Medicine Resident, Division of Rheumatology, Western University of Canada; J. Kraft, MD, Dermatologist; C. Lynde, MD, Dermatologist, Lynde Dermatology; J. Pope, MD, Professor of Rheumatology, Division of Rheumatology, Western University of Canada; W. Gulliver, MD, Professor

Personal non-commercial use only. The Journal of Rheumatology Copyright @ 2015 . All rights reserved. 
of Medicine, Faculty of Medicine, Memorial University of Newfoundland; S. Keeling, MD, Associate Professor of Rheumatology, Division of Rheumatology, University of Alberta; J. Dutz, MD, Professor of Dermatology, Department of Dermatology and Skin Science, University of British Columbia; L. Bessette, MD, Associate Professor of Medicine, Centre de Recherche du CHU de Québec, Department of Medicine, Laval University; R. Bissonnette, MD, Medical Director, Innovaderm Research, B. Haraoui, MD, Head of Clinical Research Unit, Institut de Rhumatologie de Montréal.

Address correspondence to Dr. B. Haraoui, Institut de Rhumatologie de Montreal, 1551 Ontario St. East, Montreal, Quebec H2L 1S6, Canada. E-mail: boulos.haraoui@ssss.gouv.qc.ca

Full Release Article. For details see Reprints/Permissions at jrheum.org. Accepted for publication May 4, 2015.

Patients with rheumatoid arthritis (RA), psoriatic arthritis (PsA), and psoriasis ( $\mathrm{PsO})$ are at increased risk of comorbidities such as cardiovascular diseases (CVD; likely related to accelerated atherosclerosis and systemic inflammation), osteoporosis, depression, infections, and cancer ${ }^{1,2}$.

Comorbidities should be considered when managing patients with $\mathrm{RA}^{3}$, PsA, or $\mathrm{PsO}^{4}$, because these conditions contribute to increased early mortality, affect disease activity and response to treatments, and generate costs in these populations ${ }^{5}$. Further, medications used to manage the underlying inflammatory condition, including disease-modifying antirheumatic drugs (DMARD), tumor necrosis factor inhibitors (TNFi), corticosteroids (CS), and nonsteroidal antiinflammatory drugs (NSAID), may also increase or, conversely, decrease the likelihood of comorbidities.

The Canadian Dermatology-Rheumatology (DR) Comorbidity Initiative has combined scientific evidence with the clinical expertise of a panel of Canadian rheumatologists and dermatologists to develop detailed, evidence-based, practical recommendations for managing comorbidities in patients with RA, PsA, or PsO, in line with the 3E Initiative (Evidence, Expertise, Exchange) in rheumatology ${ }^{6}$. The target population for these recommendations is adults (aged $>18$ yrs) with RA, PsA, or PsO, and the target users are rheumatologists, dermatologists, and other healthcare providers who treat patients with these conditions and who should be aware of specific comorbidity management.

\section{MATERIALS AND METHODS}

The Canadian DR Comorbidity Initiative group consisted of a steering committee, a bibliographic team, and an expert committee. The steering committee included 2 co-chairs [1 rheumatologist $(\mathrm{BH})$ and 1 dermatologist (RB)], as well as 6 members [3 rheumatologists (LB, SK, and JP) and 3 dermatologists (JD, WG, and CL)]. The bibliographic team included 4 rheumatology trainees (CR, TS, AM, and SS) and 4 dermatology trainees (VR, CM, PF, and JK) who conducted the literature reviews. Eight Canadian rheumatologists and dermatologists from across Canada formed the expert committee (MK, DL, JT, ES, MB, PL, MG, and CH) that reviewed the evidence from the literature reviews and contributed to formulate practice recommendations.

The focus of the initiative was on comorbidities shared by RA and $\mathrm{PsO} / \mathrm{Ps} \mathrm{A}$. A comorbidity was defined as a condition that is associated with RA or PsO/PsA, but is not a systemic manifestation of the disease.

A Delphi voting process was used to select the comorbidities addressed in this review. The 8 comorbidity topics that obtained the highest level of agreement in the Delphi vote (including CVD risk and outcomes, smoking, weight, malignancies, infections, osteoporosis, and depression) were then reformulated into searchable terms, according to the Population, Intervention, Comparison, Outcome method ${ }^{7}$. Each question could be subdivided into several parts to cover all facets of the topic, resulting in a total of 21 questions. A systematic literature review was performed for each question. Other comorbidities, such as chronic obstructive pulmonary disease/asthma, impaired renal function, and hypertension (HTN) were proposed, but did not get enough votes to be in the 8 selected topics.

A search of MEDLINE (by PubMed), Cochrane, and EMBASE databases from 1960 to December 2012, restricted to articles published in English, was carried out by the bibliographic team with the help of experienced librarians. The proceedings of relevant annual scientific meetings [American College of Rheumatology, European League Against Rheumatism (EULAR), American Academy of Dermatology, and European Academy of Dermatology and Venereology] from 2010 to 2012 were also searched. Additional references were identified by a hand search of reference lists from key articles. Titles, abstracts, and the full text of retrieved articles were screened according to predefined inclusion and exclusion criteria. Selected studies were reviewed for methodological quality assessment according to the levels of evidence of the Oxford Centre for Evidence-Based Medicine (www.cebm.net/?o=1025). Data extraction and synthesis were performed using a predefined data collection form. The evidence per question was summarized and random-effects metaanalyses performed when possible using RevMan (version 5.2) or Stata Software (version 12.0). Forest plots were constructed to summarize the adjusted relative risk (RR) estimates and their 95\% CI. Q-tests (I2) were performed to measure heterogeneity across studies.

Summaries of the literature searches for the 8 main topics were presented to the Canadian expert committee. Nineteen recommendations were established using a Delphi voting process with prespecified cutoff agreement $(75 \%)$. Committee members voted on their level of agreement using a scale of 1 to 10 ( 1 = no agreement, $10=$ full agreement $)$. If $\geq 75 \%$ of participants scored within the predetermined agreement range, then the recommendation was deemed to be agreed upon. If $<75 \%$ of participants scored within this range, the recommendation was debated and revised, and a second vote was taken (prespecified cutoff agreement of 66\%). Each recommendation could be voted on a maximum of 3 times (prespecified cutoff agreement of 50\%). Of note, all recommendations were agreed during the first round of voting. The grade of recommendation, ranging from A to D according to the levels of the related studies, was determined according to the Oxford Centre for Evidence-Based Medicine levels of evidence. The potential effect of each recommendation on practice was assessed using a Delphi vote with 3 statements: (1) "This recommendation will change my practice", (2) "This recommendation will not change my practice as it is already my practice", and (3) "This recommendation will not change my practice as I do not want to change my practice for this aspect."

This article presents the 19 recommendations while the details and results of the systematic literature review for each topic will be published separately.

\section{RESULTS}

The 8 research topics are listed in Table 1. A total of 17,575 articles were identified in the literature search, of which 407 were reviewed (Table 2). The 19 Canadian recommendations for the management of comorbidities in RA, PsA, and $\mathrm{PsO}$ are listed in Table 3, with the corresponding level of evidence and grade of recommendation. The effect on practice, as voted by the Canadian DR Comorbidity Initiative group (steering committee, bibliographic fellows, and expert committee), is reported in Table 4.

Recommendation 1. Individuals with RA, PsA, and PsO have

Personal non-commercial use only. The Journal of Rheumatology Copyright (C) 2015. All rights reserved. 
Table 1. Eight research questions relating to comorbidities in patients with RA, PsA, or PsO formulated by the Canadian Dermatology-Rheumatology Comorbidity Initiative.

\begin{tabular}{ll}
\hline Question & Description \\
\hline 1. & What are the risks of CVD in patients with RA, PsA, and PsO, including the effect of disease severity, disease duration, and comparison \\
with traditional CV risk factors? \\
Does the treatment of RA, PsA, and PsO with systemic agents have an effect on CV outcomes? \\
S. \\
Smoking: What is the prevalence of smoking in patients with RA, PsA, or PsO? What effect does smoking have on disease activity? What is \\
the efficacy of smoking cessation strategies in terms of disease activity and response to treatment? \\
Weight: Does weight/BMI relate to disease activity in RA, PsA, and PsO? What is the effect of treatment on weight? What is the effect of \\
weight on response to treatment? What is the effect of weight management on disease activity? \\
Other comorbidities: Are there any differences in malignancies and infections between patients with RA, PsA, and PsO? How common are \\
malignancies and infections in these populations? What is the effect of treatment on malignancies and infections? \\
Malignancies: Is there an increased risk of cancer recurrence or new cancers in patients with RA, PsA, or PsO with previous cancer treated \\
7. \\
with traditional DMARD or biologic DMARD? \\
Osteoporosis: Is osteoporosis related to disease activity and biomarkers? What is the effect of treatment on osteoporosis? \\
Depression: What is the prevalence of depression in patients with RA, PsA, or PsO? What are the risk factors for depression? What is the \\
effect of treatment on depression?
\end{tabular}

RA: rheumatoid arthritis; PsA: psoriatic arthritis; PsO: psoriasis; CVD: cardiovascular diseases; CV: cardiovascular; BMI: body mass index; DMARD: disease-modifying antirheumatic drugs.

Table 2. Results of the systematic literature search for each of the 8 recommendation topics. Values are $\mathrm{n}$.

\begin{tabular}{lcc}
\hline Recommendations & $\begin{array}{c}\text { References } \\
\text { Identified by } \\
\text { Systematic Literature } \\
\text { Search }\end{array}$ & $\begin{array}{c}\text { References } \\
\text { Included in the } \\
\text { Systematic } \\
\text { Reviews }\end{array}$ \\
\hline Risks of CV disease & 3457 & 110 \\
Effect of treatment on CV disease & 2630 & 34 \\
Smoking & 1140 & 66 \\
Weight & 2108 & 88 \\
Malignancies and infections & 1993 & 47 \\
Risk of cancer recurrence or new & & \\
$\quad$ cancer linked to treatment & 3428 & 6 \\
Osteoporosis & 2280 & 40 \\
Depression & 539 & 16 \\
Total & 17,575 & 407 \\
\hline
\end{tabular}

CV: cardiovascular.

a greater risk of CVD than the general population. The diseases themselves and traditional risk factors contribute to this risk. The risk of myocardial infarction (MI) in RA is comparable to that in diabetes mellitus. This should be recognized by healthcare providers and patients (Grade of Recommendation: C).

Recommendation 2. Traditional modifiable risk factors should be screened for and managed appropriately to reduce the risk of CVD in RA, PsA, and PsO populations (Grade of Recommendation: D).

Based on our metaanalyses, patients with RA experience increased risk of all-cause early mortality (RR $1.59,95 \%$ CI $1.47-1.71,50$ studies) and CV mortality (RR $1.58,95 \%$ CI $1.47-1.70,36$ studies) compared with nonrheumatic populations, as well as elevated risk of overall CVD (RR 1.66, 95\%
CI $1.51-1.82,11$ studies) $)^{8}$. Our metaanalyses showed that patients with $\mathrm{PsO}$ also have increased risk of $\mathrm{CV}$ mortality (RR 1.32,95\% CI 1.12-1.57, 7 studies), CVD (RR 1.29, 95\% CI 1.11-1.50, 5 studies), and all other CV outcomes [including peripheral artery disease (PAD), cerebrovascular accident, MI, and ischemic heart disease], but not all-cause early mortality ${ }^{8}$. Based on our metaanalysis of 6 trials, patients with PsA also have higher risk of early all-cause mortality (RR $1.46,95 \%$ CI 1.03-2.07) and CV mortality (RR $1.61,95 \%$ CI $1.09-2.38$ ) relative to the nonpsoriatic population ${ }^{8}$. No significant increase in risk of overall CVD was demonstrated for patients with PsA because of the paucity of data, although an increase in PAD and heart failure (HF) was found.

Using rheumatoid factor (RF) as a marker of increased disease severity, studies reported either an increased all-cause mortality rate ${ }^{9,10,11}$ or no difference in all-cause mortality rate $^{12}$ in RF-positive patients compared with RF-negative patients. No studies showed increased CV mortality in RF-positive patients, although some argued for an increased $\mathrm{CV}$ event (CVE) rate ${ }^{13,14}$. Moreover, general trends toward increased rates of various $\mathrm{CV}$ and mortality outcomes were found in patients with RA with more severe disease (erosive joint disease, extraarticular features, increased active joints, and lower functional class) ${ }^{11,13,14,15,16,17,18}$ and in patients with $\mathrm{PsO}$ with more severe disease ${ }^{19,20,21}$. No studies assessing the relationship between PsA severity and CV outcomes were found. In RA, PsA, and PsO, no clear association was reported between all-cause mortality, CV mortality, MI, or CVD and disease duration, which was inconsistently defined across studies.

After correcting for confounders, multiple studies also showed that $\mathrm{RA}^{22,23,24,25}$ and $\mathrm{PsO}^{26,27,28}$ are independent risk factors for various $\mathrm{CV}$ outcomes. One study ${ }^{24}$ demonstrated 
Table 3. Recommendations for the management of comorbidities in RA, PsA, and PsO from the Canadian Dermatology-Rheumatology Comorbidity Initiative. Listed according to the levels of evidence and grades of recommendations of the Oxford Centre for Evidence-Based Medicine (www.cebm.net/?o=1025).

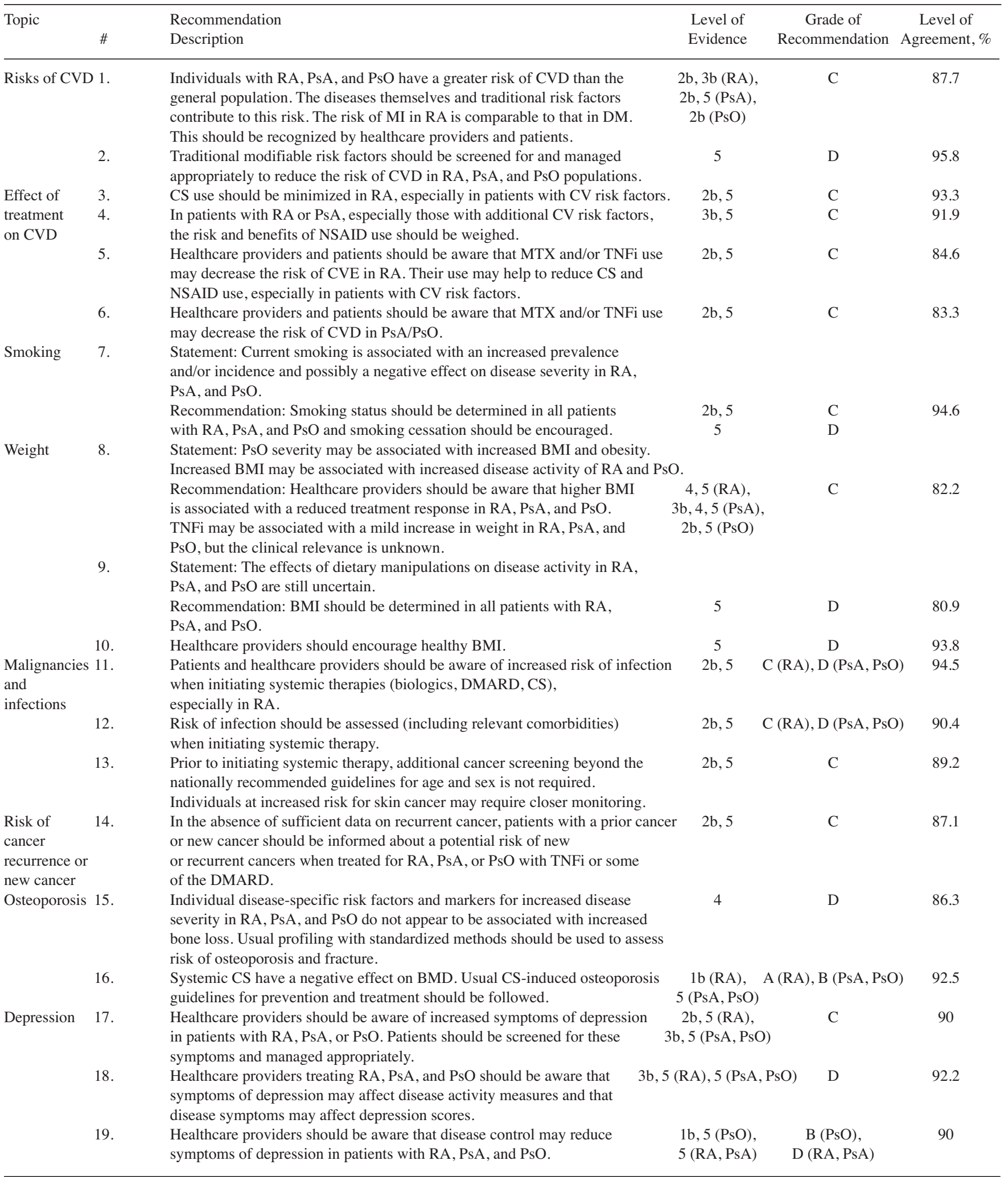

RA: rheumatoid arthritis; PsA: psoriatic arthritis; PsO: psoriasis; CVD: cardiovascular diseases; MI: myocardial infarction; DM: diabetes mellitus; CS: corticosteroids; CV: cardiovascular; NSAID: nonsteroidal antiinflammatory drugs; MTX: methotrexate; TNFi: tumor necrosis factor inhibitors; CVE: cardiovascular events; BMI: body mass index; DMARD: disease-modifying antirheumatic drugs; BMD: bone mineral density. 
Table 4. Effect of recommendation for comorbidity management on clinical practice, as voted by the Canadian Dermatology-Rheumatology Comorbidity Initiative group (steering committee, bibliographic fellows, and expert committee). Of note, recommendation 3 has no available data because of a technical failure of the voting system. Values are \%.

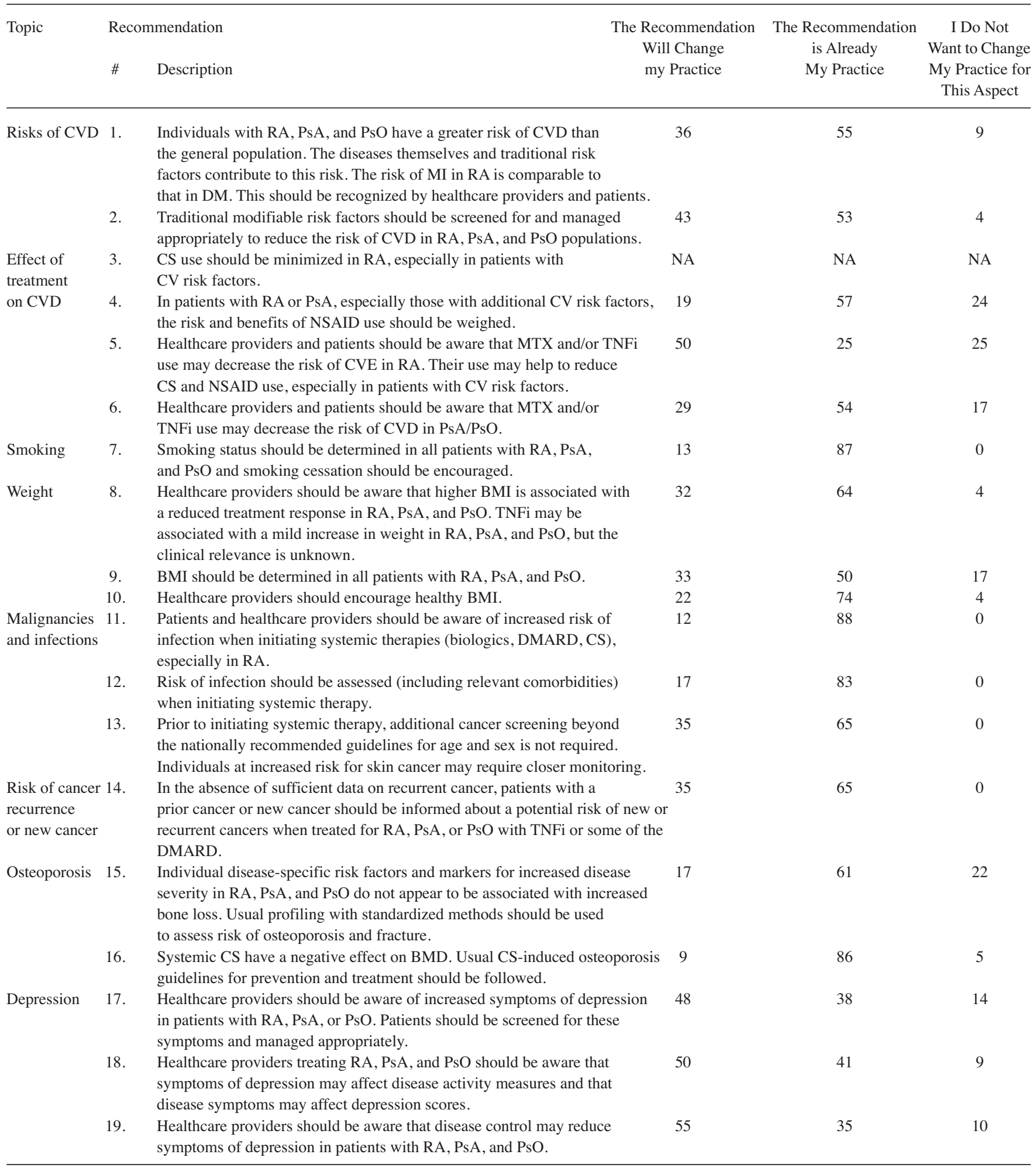

RA: rheumatoid arthritis; PsA: psoriatic arthritis; PsO: psoriasis; CVD: cardiovascular diseases; MI: myocardial infarction; DM: diabetes mellitus; CS: corticosteroids; CV: cardiovascular; NSAID: nonsteroidal antiinflammatory drugs; MTX: methotrexate; TNFi: tumor necrosis factor inhibitors; CVE: cardiovascular events; BMI: body mass index; DMARD: disease-modifying antirheumatic drugs; BMD: bone mineral density; NA: not available.

Personal non-commercial use only. The Journal of Rheumatology Copyright @ 2015 . All rights reserved. 
that RA and diabetes mellitus pose a similar risk for MI. There were no data specifically for PsA.

The whole group agreed that randomized controlled trials are required to determine whether targeting traditional CV risk factors affects $\mathrm{CV}$ mortality and morbidity in patients with RA, PsA, or PsO, and that further research should define high-risk patients with $\mathrm{CV}$ and develop appropriate targets.

Recommendation 3. CS use should be minimized in RA, especially in patients with CV risk factors (Grade of Recommendation: C).

Recommendation 4. In patients with RA or PsA, especially those with additional $\mathrm{CV}$ risk factors, the risks and benefits of NSAID use should be weighed (Grade of Recommendation: C).

Few studies have evaluated the effect of CS or NSAID specifically on CVE in patients with RA (11 studies for CS and 8 studies for NSAID). Our metaanalyses showed that risk of all CVE was increased by use of both CS (RR 1.47, 95\% CI 1.34-1.60) and NSAID (RR 1.18, 95\% CI 1.01-1.38) ${ }^{29}$. In RA, CS use increased the risk of all $\mathrm{CV}$ outcomes, including MI, HF, stroke, and major adverse cardiac events (MACE), while NSAID [including both cyclooxygenase (COX)-2 inhibitors and nonselective NSAID] increased stroke risk, but demonstrated no significant effect on MI, HF, or MACE. Use of COX-2 inhibitors significantly increased the risk of all CVE (RR 1.36, 95\% CI 1.10-1.67) whereas nonselective NSAID did not (RR 1.08, 95\% CI 0.94-1.24) ${ }^{29}$. It is, however, noteworthy that some studies assessing the COX-2 inhibitor rofecoxib, which has already been withdrawn from the market, were included in the metaanalysis. Hence, we performed separate metaanalyses for rofecoxib and another COX-2 inhibitor, celecoxib ${ }^{29}$. While rofecoxib increased the risk of all CVE (RR 1.58, 95\% CI 1.24-2.00), celecoxib did not (RR 1.03, 95\% CI 0.80-1.32). No specific studies on the CV effects of CS or NSAID in PsA or $\mathrm{PsO}$ were found. However, the whole group agreed that the present recommendation for patients with RA regarding NSAID should be extrapolated to patients with PsA with coexisting $\mathrm{CV}$ risk factors.

Recommendation 5. Healthcare providers and patients should be aware that methotrexate (MTX) and/or TNFi use may decrease the risk of CVE in RA. Their use may help to reduce $\mathrm{CS}$ and NSAID use, especially in patients with CV risk factors (Grade of Recommendation: C).

The risk of CVE was significantly decreased by use of TNFi (RR 0.70, 95\% CI 0.54-0.90) or MTX (RR 0.72, 95\% CI $0.57-0.91$; metaanalysis of 16 and 8 studies, respectively) ${ }^{29}$. TNFi specifically decreased the risk of MI (RR 0.59 , 95\% CI 0.36-0.97), stroke (RR 0.57, 95\% CI $0.35-0.92$ ), and MACE (RR $0.30,95 \%$ CI $0.15-0.57$ ), but had no significant effect on HF risk (RR $0.75,95 \%$ CI $0.49-1.15$ ). MTX specifically decreased the risk of MI (RR $0.81,95 \%$ CI $0.68-0.96$ ) and had a tendency to reduce HF (RR $0.80,95 \%$ CI 0.60-1.00); however, no significant effect on stroke (RR 0.78, 95\% CI 0.40-1.50) or MACE (RR 0.38, 95\% CI 0.05-2.84) was found, probably because of insufficient data.

Recommendation 6 . Healthcare providers and patients should be aware that MTX and/or TNFi use may decrease risk of CVD in PsA/PsO (Grade of Recommendation: C).

Less evidence regarding the effect of therapy on CVE was found in PsA and PsO compared with RA. Our metaanalysis of 6 studies evaluated the pooled effect of any systemic therapy (including phototherapy) compared with topical treatment or the absence of systemic therapy on all CVE in $\mathrm{PsA}$ and $\mathrm{PsO}$. This showed that systemic therapy significantly decreased the risk of all CVE in PsA and PsO (RR 0.75, 95\% CI $0.63-0.91)^{29}$. No stratification according to specific treatment or individual $\mathrm{CV}$ endpoint could be performed.

Recommendation 7. Smoking status should be determined in all patients with RA, PsA, and PsO (Grade of Recommendation $\mathrm{C}$ ) and smoking cessation should be encouraged (Grade of Recommendation: D).

Our metaanalysis of 19 studies showed an RR for current smoking of 1.49 (95\% CI 1.20-1.85) in patients with RA compared with patients without RA. Sensitivity analyses revealed that the RR for current smoking was maintained in patients with RA when evaluated in the following subgroups: men (RR 1.84, 95\% CI 1.53-2.21), women (RR 1.21, 95\% CI 1.02-1.64), patients with early RA (RR $1.35,95 \%$ CI 1.25-1.45), patients with established RA (RR $1.36,95 \%$ CI 1.22-1.52), current smokers (RR 1.43, 95\% CI 1.34-1.53), and ex-smokers (RR 1.17, 95\% CI 1.06-1.29). Interestingly, an increased prevalence of current smoking was found in RF-positive patients (RR 1.56, 95\% CI 1.32-1.84), but not RF-negative patients, and anticitrullinated protein antibodies (ACPA)-positive patients (RR 1.64, 95\% CI 1.45-1.84), but not ACPA-negative patients. Very limited and heterogeneous evidence suggested some association between smoking and greater disability in RA [as assessed by the Health Assessment Questionnaire (HAQ) $]^{30,31}$, but no significant association was found between smoking and other markers of disease activity, such as Disease Activity Score at 28 joints (DAS28), erythrocyte sedimentation rate (ESR), C-reactive protein (CRP), or the Larsen score for radiographic joint damage. No study was found that evaluated the effect of smoking cessation on RA disease severity.

In $\mathrm{PsO}$, our metaanalysis pooling data from 22 studies showed an RR for current smoking of 1.88 (95\% CI 1.66-2.13) in patients with $\mathrm{PsO}$ compared with individuals without PsO. Various sensitivity analyses confirmed the increased prevalence of smoking in patients with PsO. Current smokers were found to have an RR of new-onset $\mathrm{PsO}$ of 1.94 (95\% CI 1.64-2.28) compared with never smokers ${ }^{32}$. No clear association was found between PsO severity and smoking intensity, which was inconsistently defined across studies. While 8 studies suggested that increased PsO disease severity may be related to cigarette smoking $33,34,35,36,37,38,39,40$,

Personal non-commercial use only. The Journal of Rheumatology Copyright $\odot$ 2015. All rights reserved. 
3 other studies did $\operatorname{not}^{41,42,43}$. An RR of 3.12 (95\% CI 2.07-4.69) for current smoking in new-onset $\mathrm{PsA}^{44}$ and worse self-reported pain scores in smokers with PsA ${ }^{45}$ were reported.

Therefore, the whole group agreed that current smoking is associated with RA, PsA, and PsO, and possibly has a negative effect on disease severity. Smoking is also associated with multiple well-established health issues, for which patients with RA, PsA, and PsO may already be at an increased risk. Thus, despite the absence of data on the effect of smoking cessation on RA, PsA, and PsO disease severity, smoking status should be determined in all patients with RA, PsA, and PsO, and smoking cessation encouraged.

Recommendation 8 . Healthcare providers should be aware that higher body mass index (BMI) is associated with a reduced treatment response in RA, PsA, and PsO. TNFi may be associated with a mild increase in weight in RA, PsA, and $\mathrm{PsO}$, but the clinical relevance is unknown (Grade of Recommendation: C).

Recommendation 9. BMI should be determined in all patients with RA, PsA, and PsO (Grade of Recommendation: D).

Recommendation 10. Healthcare providers should encourage healthy BMI (Grade of Recommendation: D).

No clear association between weight and disease activity or severity could be evidenced in RA. Conflicting heterogeneous studies provided mixed data that could not be pooled in a metaanalysis. Although BMI in the obese range was associated with more disease activity ${ }^{46,47}$, some studies also found an association between higher BMI and lower mortality ${ }^{48}$, lower rate of erosion changes ${ }^{49}$, and less severe disease in ACPA-positive patients ${ }^{49}$, and between decreased BMI or cachexia and increased early mortality ${ }^{50,51}$, increased disability $^{52}$, and increased joint space narrowing ${ }^{53}$. Finally, 2 studies did not find any association between BMI and RA disease activity ${ }^{54,55}$.

In $\mathrm{PsO}$, disease severity may be associated with increased BMI or obesity $43,56,57,58,59,60$. PsO was also reported to be associated with obesity or BMI $>25 \mathrm{~kg} / \mathrm{m}^{2}$, regardless of severity $61,62,63$. In PsA, only 2 studies suggested that higher weight or BMI was associated with increased incidence of $\mathrm{PsA}^{57,64}$, and no studies were found that assessed the relationship between PsA severity and BMI.

TNFi have been associated with weight gain in $\mathrm{RA}^{65}$, $\mathrm{PsA}^{66}$, and $\mathrm{PsO}^{67,68}$. Obese patients with $\mathrm{PsO}^{69,70,71,72}$, $\mathrm{PsA}^{73,74,75}$, or $\mathrm{RA}^{76,77}$ may have a reduced response to treatment compared with nonobese patients, especially to biologic agents. Additionally, obese patients with $\mathrm{PsO}$ with a moderate-to-severe disease may increase their response to low-dose cyclosporine if a calorie-controlled diet is included in their treatment regimen ${ }^{78}$, and bariatric surgery in obese patients with $\mathrm{PsO}$ was found to improve $\mathrm{PsO}$ in very small case series ${ }^{79,80}$. The effects of dietary interventions on RA disease activity are uncertain ${ }^{81}$.

Recommendation 11. Patients and healthcare providers should be aware of increased risk of infection when initiating systemic therapies (biologics, DMARD, CS), especially in RA (Grade of Recommendation C for RA, and Grade of Recommendation D for PsA and PsO).

Recommendation 12. Risk of infection should be assessed (including relevant comorbidities) when initiating systemic therapy (Grade of Recommendation C for RA, and Grade of Recommendation D for PsA and PsO).

Based on 7 studies, the average incidence rate of serious infections (defined as infections requiring hospitalization or treatment with intravenous antibiotics, without considering opportunistic infections) in subjects treated with TNFi was higher in RA [5/100 person-yrs (PY)] than in PsA $(1.5 / 100$ $\mathrm{PY})$ or PsO (1/100 PY). Our metaanalysis solely included studies that reported incidence rates of serious infections. An increased risk of serious infections was found in subjects treated with systemic therapy, although there was stronger evidence in RA with 14 studies (RR 1.62, 95\% CI 1.36-1.93) compared with 2 studies in PsO (RR 1.61, 95\% CI $1.24-2.10)^{82,83}$ and 1 in PsA (RR 1.08, 95\% CI $0.07-17.11)^{84}$. TNFi initiation appeared to be associated with a higher risk of serious infections in RA (RR 1.68, 95\% CI 1.40-2.01, based on 13 studies) than in $\mathrm{PsA}$ and $\mathrm{PsO}^{85}$, possibly related to patient comorbidities and to the more frequent use of CS in $\mathrm{RA}^{82,86,87}$. The interpretation of the $\mathrm{PsO}$ results is limited by the fact that the 2 included studies were not randomized. Therefore, the results may be related to differences in the populations exposed to treatment and those not exposed to treatment. The methodology of our metaanalysis in $\mathrm{PsO}$ was also different from a larger metaanalysis that did not find evidence of any increased risk of serious infections in patients with $\mathrm{PsO}$ treated with $\mathrm{TNFi}^{88}$. Nevertheless, the experts agreed that while the evidence in patients with PsA and PsO treated with TNFi is unclear, this class of medication may increase the risk of serious infection. It was recommended that the risk of infection be assessed when initiating systemic therapy in the 3 diseases.

Recommendation 13. Prior to initiating systemic therapy, additional cancer screening beyond the nationally recommended guidelines for age and sex is not required. Individuals at increased risk for skin cancer may require closer monitoring (Grade of Recommendation: C).

Based on data from 8 studies, the average incidence rate of overall malignancies in subjects treated with TNFi was calculated at 1.8/100 PY for RA, 0.6/100 PY for PsA, and 1.7/100 PY for PsO. Our metaanalysis in subjects treated with systemic therapy found an overall RR of malignancy of 1.25 (95\% CI 0.88-1.78) in RA and 1.12 (95\% CI 0.88-1.42) in $\mathrm{PsO}$. The RR of malignancy could not be estimated in PsA because of the lack of data. The initiation of TNFi was not associated with an increased incidence of overall malignancy in RA (RR 1.29, 95\% CI 0.88-1.89) and could not be estimated in PsA or PsO because of insufficient data $85,89,90$. Although site-specific malignancy analysis was not

Personal non-commercial use only. The Journal of Rheumatology Copyright $\odot$ 2015. All rights reserved. 
performed, previous studies have shown that the risk of non-melanoma skin cancer and melanoma may be increased, particularly in RA. TNFi may contribute to this increased risk, but results are not consistent ${ }^{85,90,91,92}$.

Recommendation 14. In the absence of sufficient data on recurrent cancer, patients with a prior cancer should be informed about a potential risk of new or recurrent cancer when treated for RA, PsA, or PsO with TNFi or some of the DMARD (Grade of Recommendation: C).

In RA, 2 cohort studies based on European registries [the Rheumatoid Arthritis Observation of Biologic Therapy cohort (RABBIT) and the British Society of Rheumatologists Biologics Registry (BSRBR)] assessing patients with RA with prior cancer ${ }^{89,93}$ and 1 cohort study of patients with cervical carcinoma in situ ${ }^{94}$ compared the risk of recurrent or new cancers in patients with RA treated with TNFi versus patients with RA treated with conventional DMARD. In the RABBIT cohort of 122 patients with 124 prior cancers, 9 recurrent cancers occurring in $8 \mathrm{TNFi}$ recipients were reported [incidence rate (IR) 45.5/1000 PY], compared with 5 recurrent cancers occurring in 5 DMARD recipients (IR $31.4 / 1000 \mathrm{PY})^{89}$. In the BSRBR cohort of 177 patients with prior cancer treated with TNFi compared to 117 patients with prior cancer treated with conventional DMARD, 13 recurrent cancers in 11 TNFi recipients and 9 cancers in 9 DMARD recipients were reported, resulting in a crude IR of 25.3 and 38.3/1000 PY, respectively ${ }^{93}$. The overall combined incidence rate ratio of recurrent malignancy was 0.87 (95\% CI 0.45-1.70) for TNFi compared with conventional DMARD. From the cohort of 238 patients with RA with a history of cervical carcinoma in situ, no genital cancer was observed in the TNFi-treated group over a median of 5.2 years of followup compared with 2 incident genital cancers in the DMARD-treated group, during a median followup of 3.9 years ${ }^{94}$. No studies were found that evaluated the risk of recurrent cancer in patients with $\mathrm{PsA}$ or $\mathrm{PsO}$ treated with TNFi compared with traditional DMARD.

Although current studies did not demonstrate an increased $\mathrm{RR}$ of recurrent or new cancer, the expert panel felt that patients treated with TNFi should be aware that they may have an increased risk of recurrent malignancy, this risk being difficult to quantify because of insufficient data from studies that included a very limited number of patients with prior cancer.

Recommendation 15. Individual disease-specific risk factors and markers for increased disease severity in RA, PsA, and $\mathrm{PsO}$ do not appear to be associated with increased bone loss. Usual profiling with standardized methods should be used to assess risk of osteoporosis and fracture (Grade of Recommendation: D).

No significant correlations were found between bone loss and disease duration, function as measured by HAQ, disease activity as measured by the DAS (RA, PsA), skin involvement as measured by the Psoriasis Area Severity
Index (PsA, PsO), joint erosions, ESR, CRP, RF (RA), ACPA (RA), and smoking status (RA). One cohort study in RA showed negative correlations between DAS and 5-year hand bone mineral density (BMD) in multivariate analysis ${ }^{95}$. Univariate analysis also showed a correlation between 5-year BMD and HAQ, RF, and CRP; however, this association was not maintained in multivariate models. Experts recommended using standardized tools/risk profiling in assessing risk of osteoporosis in patients with RA, PsA, and PsO.

Recommendation 16. Systemic CS have a negative effect on BMD. Usual CS-induced osteoporosis guidelines for prevention and treatment should be followed (Grade of Recommendation A for RA, and Grade of Recommendation $\mathrm{B}$ for PsA and $\mathrm{PsO}$ ).

In RA, our metaanalysis of randomized controlled trials that studied the effects of CS on bone loss showed an association between oral CS use and lumbar spine bone loss (mean difference in $\triangle \mathrm{BMD}-0.3,95 \% \mathrm{CI}-0.55--0.04)^{96}$. Included studies used an average daily dose of prednisone or prednisolone ranging from $6 \mathrm{mg}$ to $12 \mathrm{mg}$ for a study period ranging from 20 weeks up to 2 years. Oral CS did not have any significant effect on hip bone loss in RA during the treatment period ${ }^{97,98,99,100,101,102}$. A literature search did not yield any randomized controlled trials studying the effect of CS on bone loss in PsA or PsO. However, experts agreed that all patients who start taking systemic CS should be managed according to the usual CS-induced osteoporosis guidelines.

There is insufficient evidence to suggest a preferred route of CS administration to minimize bone loss. In 1 study, monthly administration of intramuscular CS was associated with lower hip BMD compared with placebo ${ }^{103}$. Another study found that patients who received monthly pulses of intravenous methylprednisolone required lower cumulative doses of CS and had less bone loss compared with those who received daily oral methylprednisolone ${ }^{104}$.

Recommendation 17. Healthcare providers should be aware of increased symptoms of depression in patients with RA, PsA, or PsO. Patients should be screened for these symptoms and managed appropriately (Grade of Recommendation: C).

Several studies have examined the prevalence of symptoms of depression in patients with RA, PsA, and $\mathrm{PsO}^{105,106,107,108,109,110,111}$ based on 1 or more depression rating scales that do not allow diagnosis of major depressive disorders, but can be suggestive of depression past a certain threshold. Because of the wide variability of the scales, data could not be pooled to perform a metaanalysis. In RA, a large retrospective cohort found that $15.2 \%$ of patients with RA had self-reported depression ${ }^{105}$, a prevalence that is similar to patients with noninflammatory rheumatic diseases (14.5\%), but less than patients with systemic lupus erythematosus $(32.5 \%)$ or fibromyalgia $(37.9 \%)$. A case-control study reported a prevalence of symptoms of depression of $30 \%$ in patients with $\mathrm{RA}^{106}$. Two retrospective cohorts found

Personal non-commercial use only. The Journal of Rheumatology Copyright @ 2015. All rights reserved. 
that all-cause mortality was higher in patients with both RA and depression compared with those with RA alone ${ }^{105,107 .}$

Regarding PsA, no studies were found that have compared the rate of symptoms of depression in patients with PsA to healthy controls. In a quasi-experimental study, the rate of symptoms of depression was higher in patients with both PsA and $\mathrm{PsO}$ compared with those with $\mathrm{PsO}$ alone ${ }^{108}$. For PsO, 2 case-control studies found higher rates of symptoms of depression in patients with $\mathrm{PsO}$ compared with healthy controls ${ }^{109,110}$ and another study reported that $21 \%$ of patients experienced symptoms of depression using the Beck Depression Inventory scale, which was comparable to patients with prurigo nodularis ${ }^{111}$.

Recommendation 18. Healthcare providers treating RA, PsA, and $\mathrm{PsO}$ should be aware that symptoms of depression may affect disease activity measures and that disease symptoms may affect depression scores (Grade of Recommendation D).

Some associations between RA disease activity and symptoms of depression severity were found ${ }^{106,112,113,114,115}$. A British cross-sectional study found a weak positive correlation between depressive symptom score and visual analog scale (VAS) pain score and a moderate positive correlation with depressive symptoms score and both the HAQ and the number of affected joints ${ }^{112}$. In 2 studies, depressed patients with RA were found to have higher DAS28 scores, ESR, and CRP than nondepressed patients with RA ${ }^{113,114}$. A case-control study reported a moderate positive correlation between depressive symptoms and VAS pain scores ${ }^{106}$. Moreover, in 1 RA trial, patients with clinical remission as assessed by DAS28 were less likely to have depression than nonremitters at Week 104, and reciprocally, more nondepressed patients achieved more clinical remission than those with depressive symptoms ${ }^{115}$.

Recommendation 19. Healthcare providers should be aware that disease control may reduce symptoms of depression in patients with RA, PsA, and PsO (Grade of Recommendation $\mathrm{B}$ for PsO, and Grade of Recommendation D for RA and PsA).

In addition to the study in which patients with RA with clinical remission were found less likely to have depression than those who had not achieved remission ${ }^{115}, 3$ randomized controlled trials explored the effects of biologics on symptoms of depression in $\mathrm{PsO}^{116,117,118,119}$. Patients with $\mathrm{PsO}$ treated with antiinterleukin 12/23 agents reported fewers symptoms of depression at 24 weeks ${ }^{116}$, and those treated with adalimumab ${ }^{118}$ or etanercept $(\mathrm{ETN})^{117}$ reported fewer symptoms of depression at 12 weeks. In an open-label trial, patients with $\mathrm{PsO}$ receiving ETN had reduced depression scores up to 96 weeks ${ }^{120}$. The whole group agreed that future research should evaluate the role of therapy of RA, PsA, and $\mathrm{PsO}$ in the improvement of major depression in patients.

\section{DISCUSSION}

These 19 Canadian evidence-based recommendations underline the crucial need for an integrated approach to diagnose, manage, and also prevent comorbidities in patients with RA, PsA, and PsO. Combining disease control and comorbidity management should become part of the daily practice in RA, PsA, and PsO to ensure optimal care and outcomes.

For this review, the panel of experts reached a consensus to select 8 common comorbid conditions prevalent in RA, $\mathrm{PsO}$, and PsA. Other comorbidities, such as HTN, renal impairment, and pulmonary diseases were proposed, but were not retained based on the preset limit on the number of topics that could be included. Nonetheless, our working group recognizes the importance of screening and treating other comorbidities associated with RA, PsO, and PsA. The final recommendations were reached by consensus based on evidence graded according to the Oxford Centre for Evidence-Based Medicine method. Other recommended methods could have been preferably used, such as the Grading of Recommendations Assessment, Development, and Evaluation working group approach.

To date, the CVD issue has been addressed in recommendations, such as in the EULAR recommendations for $\mathrm{RA}^{121}$; however, extrapolation to patients with PsA and PsO is needed $^{122}$. Most primary care physicians and cardiologists do not screen patients with PsO for CVD risk factors ${ }^{123}$, although this has been recommended in guidelines published by the American Cardiology Association ${ }^{124}$. Further, comorbidities are not limited to CVD burden and a more global approach is needed to include other important concerns, such as infection, malignancies, and psychiatric disorders in these patients.

Several national or professional society recommendations and guidelines for the management of RA, PsA, and PsO include screening and treatment, as well as the use of biologic agents $^{125,126}$. They have mostly focused on the screening of certain infectious diseases, such as tuberculosis and hepatitis $\mathrm{B}$ and $\mathrm{C}^{122,127}$. Regarding prior malignancies, rituximab is the biologic recommended in patients with RA with previously treated solid malignancy, a nonmalignant skin cancer within the last 5 years, melanoma, or lymphoproliferative malignancy, despite the fact that little is known about the effects of biologic therapy in patients with a solid cancer within the past 5 years ${ }^{127}$. However, besides these specific guidelines, the EULAR CVD recommendations, the Brazilian Society of Rheumatology recommendations for $\mathrm{RA}^{128}$, and recommendations from a group of French dermatologists for $\mathrm{PsO}^{129}$, no recommendations regarding the global management of comorbidities in RA, PsA, and PsO, or regarding the effect of comorbidities on the 3 diseases and the influence of RA, PsA, and PsO treatments on comorbidities have been published to date. The Brazilian recommendations underline the need for early diagnosis and management of comorbidities, including HTN, diabetes mellitus, atherosclerosis, and osteoporosis, based on multi-

Personal non-commercial use only. The Journal of Rheumatology Copyright @ 2015 . All rights reserved. 
disciplinary followup. They also recommend, among other measures, avoiding high doses of CS and/or NSAID in patients with RA who have HTN or diabetes mellitus. In PsO, the recommendations stress that the increased risk of CVD requires appropriate prevention. Nevertheless, to our knowledge, the present recommendations are the first evidence-based recommendations in the large field of comorbidities in the 3 conditions (RA, PsA, and PsO) developed with the expert opinion of both rheumatologists and dermatologists.

The rationale for the integrated management of comorbidities is based not only on an increased prevalence of comorbid conditions, but also on their potential effect on disease activity and response to treatment. In addition, RA, PsA, and PsO treatments may affect the prevalence and evolution of comorbidities. To support this point, MTX has been associated with a $70 \%$ reduction in mortality ${ }^{130}$ and a reduced risk of $C^{131,132}$ in patients with RA. TNFi may also be associated with a reduced risk of CVD in RA ${ }^{133,134}$. Increased CVD, as well as depression symptom burden, resulted in recommending awareness and risk reduction of both traditional risk factors and disease-related factors when treating patients with RA, PsA, and PsO. The risk-to-benefit ratio of NSAID should be carefully considered in patients with CV risk factors, and CS use minimized. Smoking cessation and healthy BMI should be encouraged, not only for CV concerns, but also because current smoking and higher BMI may be associated with increased disease activity in $\mathrm{RA}$ and $\mathrm{PsO}$, and higher $\mathrm{BMI}$ with a reduced response to treatment. Notably, while waist circumference is emerging as a better marker of atherosclerosis than BMI and has been associated with increased early mortality and CVD in the general population ${ }^{135,136}$, very few data exist about the relationship between waist circumference and CVD, as well as disease activity and response to treatment in $\mathrm{RA}^{47}$, PsA, or PsO. These associations should be further explored. Additionally, the global risk of infection, not limited to tuberculosis and hepatitis B and C, should be assessed when initiating systemic therapy. Standard guidelines for cancer screening in the general population and treatment and prevention of CS-induced osteoporosis should be considered.

One of the current issues is how to deal with comorbidities of RA, PsA, or PsO in clinical practice and what simple tools to use in such assessment. The practical modalities of how to screen and achieve integrated management of such comorbidities in patients with RA, PsA, and $\mathrm{PsO}$ requires systemizing and needs further specific recommendations. The frequency of monitoring should also be determined because several of these risks may change over time. Moreover, there is some confusion regarding certain issues, such as whether specific recommendations tailored to these populations, with specific targets and treatment thresholds, are required ${ }^{137}$. Given the evidence supporting the present recommendations, tight disease control (including optimal DMARD and TNFi use) combined with control of traditional CV risk factors may have a synergistic and complementary effect on CVD burden in RA, and perhaps also in PsA and PsO.

The challenges of managing such a critical health burden include the feasibility and cost of implementing recommendations in routine practice, not only for rheumatologists and dermatologists, but also for primary care physicians. The logistics of monitoring comorbidities should be taken into account to help healthcare providers integrate the management of comorbidities in their practice. A multidisciplinary care team model including physician assistants or nurse practitioners may become the new normal, with specifically defined roles for each team member. Adherence of patients to treatment recommendations should also be considered. Indeed, it can be speculated that greater understanding of the common pathways between comorbidities and RA, PsA, and PsO may improve patients' adherence to such a strategy, and in turn, increase the expected benefit.

We hope that these recommendations will be useful for all healthcare providers managing RA, PsA, and PsO, and may inform future recommendations for improving care of patients with RA, PsA, and $\mathrm{PsO}$ with comorbidities.

Because comorbidities in patients with RA, PsA, and PsO can be improved by specific preventive and therapeutic strategies, early detection and management are needed to reduce their effect. Nineteen practical evidence-based recommendations were developed, integrating literature reviews and expert opinion, with the aim of improving the management of the most frequent comorbidities encountered in RA, PsA, and PsO. A multidisciplinary and integrated approach should be encouraged to improve the patients' disease and comorbidity management. In the future, RA, PsA, and PsO management should become more patient-centered rather than joint- or skin-centered based on the coordinated effort of a network of rheumatologists, dermatologists, and other healthcare professionals.

\section{ACKNOWLEDGMENT}

The expert committee consisted of Majed Khraishi, Diane Lacaille, John Thomson, Evelyn Sutton, Marc Bourcier, Pierre-Luc Dion, Martin Gilbert, and Chih-ho Hong. The authors thank the librarians and the statisticians who assisted with the systematic searches and metaanalysis, and Virginia Wallis for her assistance with the manuscript preparation.

\section{REFERENCES}

1. Armstrong AW, Schupp C, Bebo B. Psoriasis comorbidities: results from the National Psoriasis Foundation surveys 2003 to 2011. Dermatology 2012;225:121-6.

2. Dougados M, Soubrier M, Antunez A, Balint P, Balsa A, Buch MH, et al. Prevalence of comorbidities in rheumatoid arthritis and evaluation of their monitoring: results of an international, cross-sectional study (COMORA). Ann Rheum Dis 2014;73:62-8.

3. Haraoui B, Liu PP, Papp KA. Managing cardiovascular risk in patients with chronic inflammatory diseases. Clin Rheumatol 2012;31:585-94.

4. Gulliver W. Long-term prognosis in patients with psoriasis. Br J

Personal non-commercial use only. The Journal of Rheumatology Copyright @ 2015 . All rights reserved. 
Dermatol 2008;159 Suppl 2:2-9.

5. Kimball AB, Guerin A, Tsaneva M, Yu AP, Wu EQ, Gupta SR, et al. Economic burden of comorbidities in patients with psoriasis is substantial. J Eur Acad Dermatol Venereol 2011;25:157-63.

6. Visser K, Katchamart W, Loza E, Martinez-Lopez JA, Salliot C, Trudeau J, et al. Multinational evidence-based recommendations for the use of methotrexate in rheumatic disorders with a focus on rheumatoid arthritis: integrating systematic literature research and expert opinion of a broad international panel of rheumatologists in the 3E Initiative. Ann Rheum Dis 2009;68:1086-93.

7. Sackett DL, Richardson WS, Rosenberg WM, Haynes RB. Evidence-based medicine: how to practice and teach EBM. London: Churchill Livingstone; 1997.

8. McFarlane A, Roubille C, Richer V, Starnino T, McCourt C, Fleming P, et al. Cardiovascular outcomes in patients with rheumatoid arthritis, psoriasis and psoriatic arthritis: a systematic review and meta-analyses. Ann Rheum Dis 2014;73 Suppl 2:324-5.

9. Goodson N, Marks J, Lunt M, Symmons D. Cardiovascular admissions and mortality in an inception cohort of patients with rheumatoid arthritis with onset in the 1980s and 1990s. Ann Rheum Dis 2005;64:1595-601.

10. Gonzalez A, Icen M, Kremers HM, Crowson CS, Davis JM 3rd, Therneau TM, et al. Mortality trends in rheumatoid arthritis: the role of rheumatoid factor. J Rheumatol 2008;35:1009-14.

11. Mitchell DM, Spitz PW, Young DY, Bloch DA, McShane DJ, Fries JF. Survival, prognosis, and causes of death in rheumatoid arthritis. Arthritis Rheum 1986;29:706-14.

12. Goodson NJ, Wiles NJ, Lunt M, Barrett EM, Silman AJ, Symmons DP. Mortality in early inflammatory polyarthritis: cardiovascular mortality is increased in seropositive patients. Arthritis Rheum 2002;46:2010-9.

13. Scott IC, Ibrahim F, Johnson D, Scott DL, Kingsley GH. Current limitations in the management of cardiovascular risk in rheumatoid arthritis. Clin Exp Rheumatol 2012;30:228-32 .

14. Serelis J, Panagiotakos DB, Mavrommati M, Skopouli FN. Cardiovascular disease is related to hypertension in patients with rheumatoid arthritis: a Greek cohort study. J Rheumatol 2011;38:236-41.

15. Peltomaa R, Paimela L, Kautiainen H, Leirisalo-Repo M. Mortality in patients with rheumatoid arthritis treated actively from the time of diagnosis. Ann Rheum Dis 2002;61:889-94.

16. Turesson C, Jacobsson L, Bergström U. Extra-articular rheumatoid arthritis: prevalence and mortality. Rheumatology 1999;38:668-74.

17. Young A, Koduri G, Batley M, Kulinskaya E, Gough A, Norton S, et al; Early Rheumatoid Arthritis Study (ERAS) group. Mortality in rheumatoid arthritis. Increased in the early course of disease, in ischaemic heart disease and in pulmonary fibrosis. Rheumatology 2007;46:350-7.

18. Heliövaara M, Aho K, Knekt P, Aromaa A, Maatela J, Reunanen A. Rheumatoid factor, chronic arthritis and mortality. Ann Rheum Dis 1995;54:811-4.

19. Mallbris L, Akre O, Granath F, Yin L, Lindelof B, Ekbom A, et al. Increased risk for cardiovascular mortality in psoriasis inpatients but not in outpatients. Eur J Epidemiol 2004;19:225-30.

20. Stern RS, Huibregtse A. Very severe psoriasis is associated with increased noncardiovascular mortality but not with increased cardiovascular risk. J Invest Dermatol 2011;131:1159-66.

21. Yang YW, Keller JJ, Lin HC. Medical comorbidity associated with psoriasis in adults: a population-based study. Br J Dermatol 2011;165:1037-43.

22. del Rincón ID, Williams K, Stern MP, Freeman GL, Escalante A. High incidence of cardiovascular events in a rheumatoid arthritis cohort not explained by traditional cardiac risk factors. Arthritis Rheum 2001;44:2737-45

23. Wolfe F, Freundlich B, Straus WL. Increase in cardiovascular and cerebrovascular disease prevalence in rheumatoid arthritis. J Rheumatol 2003;30:36-40.

24. Lindhardsen J, Ahlehoff O, Gislason GH, Madsen OR, Olesen JB, Torp-Pedersen C, et al. The risk of myocardial infarction in rheumatoid arthritis and diabetes mellitus: a Danish nationwide cohort study. Ann Rheum Dis 2011;70:929-34

25. Mikuls TR, Saag KG, Criswell LA, Merlino LA, Kaslow RA, Shelton BJ, et al. Mortality risk associated with rheumatoid arthritis in a prospective cohort of older women: results from the Iowa Women's Health Study. Ann Rheum Dis 2002;61:994-9.

26. Gelfand JM, Neimann AL, Shin DB, Wang X, Margolis DJ, Troxel AB. Risk of myocardial infarction in patients with psoriasis. JAMA 2006;296:1735-41.

27. Gelfand JM, Dommasch ED, Shin DB, Azfar RS, Kurd SK, Wang $\mathrm{X}$, et al. The risk of stroke in patients with psoriasis. J Invest Dermatol 2009;129:2411-8.

28. Mehta NN, Azfar RS, Shin DB, Neimann AL, Troxel AB, Gelfand JM. Patients with severe psoriasis are at increased risk of cardiovascular mortality: cohort study using the General Practice Research Database. Eur Heart J 2010;31:1000-6.

29. Roubille C, Richer V, Starnino T, McCourt C, McFarlane A, Fleming $\mathrm{P}$, et al. The effects of tumour necrosis factor inhibitors, methotrexate, non-steroidal anti-inflammatory drugs and corticosteroids on cardiovascular events in rheumatoid arthritis, psoriasis and psoriatic arthritis: a systematic review and meta-analysis. Ann Rheum Dis 2015;74:480-9.

30. Finckh A, Dehler S, Costenbader KH, Gabay C; Swiss Clinical Quality Management project for RA. Cigarette smoking and radiographic progression in rheumatoid arthritis. Ann Rheum Dis 2007;66:1066-71

31. Mattey DL, Hutchinson D, Dawes PT, Nixon NB, Clarke S, Fisher $\mathrm{J}$, et al. Smoking and disease severity in rheumatoid arthritis: association with polymorphism at the glutathione S-transferase M1 locus. Arthritis Rheum 2002;46:640-6.

32. Li W, Han J, Choi HK, Qureshi AA. Smoking and risk of incident psoriasis among women and men in the United States: a combined analysis. Am J Epidemiol 2012;175:402-13.

33. Ahdout J, Kotlerman J, Elashoff D, Kim J, Chiu MW. Modifiable lifestyle factors associated with metabolic syndrome in patients with psoriasis. Clin Exp Dermatol 2012;37:477-83.

34. Attwa E, Swelam E. Relationship between smoking-induced oxidative stress and the clinical severity of psoriasis. J Eur Acad Dermatol Venereol 2011;25:782-7.

35. Gupta MA, Gupta AK, Watteel GN. Cigarette smoking in men may be a risk factor for increased severity of psoriasis of the extremities Br J Dermatol 1996;135:859-60.

36. Zhang X, Wang H, Te-Shao H, Yang S, Wang F. Frequent use of tobacco and alcohol in Chinese psoriasis patients. Int J Dermatol 2002;41:659-62.

37. Davidsson S, Blomqvist K, Molin L, Mørk C, Sigurgeirsson B, Zachariae H, et al. Lifestyle of Nordic people with psoriasis. Int J Dermatol 2005;44:378-83.

38. Fernandez-Torres RM, Paradela S, Fonseca E. Psoriasis in patients older than 65 years. A comparative study with younger adult psoriatic patients. J Nutr Health Aging 2012;16:586-91.

39. Fortes C, Mastroeni S, Leffondre K, Sampogna F, Melchi F, Mazzotti E, et al. Relationship between smoking and the clinical severity of psoriasis. Arch Dermatol 2005;141:1580-4.

40. Demirseren DD, Emre S, Akoğlu G, Kılıç S, Metin A. Evaluation of effects of smoking and body mass index on clinical severity of psoriasis. Proceedings of 21st Congress of the EADV 2012, Sept 27-30; Prague: Congress of the EADV; 2012P: 958

41. Jiamton S, Suthipinittharm P, Kulthanan K, Chularojanamontri L, Wongpraparut C, Silpa-archa N, et al. Clinical characteristics of Thai patients with psoriasis. J Med Assoc Thai 2012;95:795-801 
42. Neimann AL, Shin DB, Wang X, Margolis DJ, Troxel AB, Gelfand JM. Prevalence of cardiovascular risk factors in patients with psoriasis. J Am Acad Dermatol 2006;55:829-35.

43. Wolk K, Mallbris L, Larsson P, Rosenblad A, Vingård E, Ståhle M. Excessive body weight and smoking associates with a high risk of onset of plaque psoriasis. Acta Derm Venereol 2009;89:492-7.

44. Lan CC, Ko YC, Yu HS, Wu CS, Li WC, Lu YW, et al. Methotrexate reduces the occurrence of cerebrovascular events among Taiwanese psoriatic patients: a nationwide population-based study. Acta Derm Venereol 2012;92:349-52.

45. Bremander AB, Petersson IF, Haglund E, Bergman S, Jacobsson LT. Smoking is associated with worse and more widespread pain, worse fatigue, general health and quality of life in a Swedish population based cohort of patients with psoriatic arthritis. Arthritis Rheum 2012;64 Suppl 10:1828.

46. Karvounaris SA, Sidiropoulos PI, Papadakis JA, Spanakis EK, Bertsias GK, Kritikos HD, et al. Metabolic syndrome is common among middle-to-older aged Mediterranean patients with rheumatoid arthritis and correlates with disease activity: a retrospective, cross-sectional, controlled, study. Ann Rheum Dis 2007;66:28-33

47. Ajeganova S, Andersson ML, Hafström I; BARFOT Study Group. Association of obesity with worse disease severity in rheumatoid arthritis as well as with comorbidities: a long-term followup from disease onset. Arthritis Care Res 2013;65:78-87.

48. Escalante A, Haas RW, del Rincón I. Paradoxical effect of body mass index on survival in rheumatoid arthritis: role of comorbidity and systemic inflammation. Arch Intern Med 2005;165:1624-9.

49. van der Helm-van Mil AH, van der Kooij SM, Allaart CF, Toes RE, Huizinga TW. A high body mass index has a protective effect on the amount of joint destruction in small joints in early rheumatoid arthritis. Ann Rheum Dis 2008;67:769-74.

50. Mikuls TR, Fay BT, Michaud K, Sayles H, Thiele GM, Caplan L, et al. Associations of disease activity and treatments with mortality in men with rheumatoid arthritis: results from the VARA registry. Rheumatology 2011;50:101-9.

51. Kremers HM, Nicola PJ, Crowson CS, Ballman KV, Gabriel SE. Prognostic importance of low body mass index in relation to cardiovascular mortality in rheumatoid arthritis. Arthritis Rheum 2004;50:3450-7.

52. Engvall IL, Elkan AC, Tengstrand B, Cederholm T, Brismar K, Hafstrom I. Cachexia in rheumatoid arthritis is associated with inflammatory activity, physical disability, and low bioavailable insulin-like growth factor. Scand J Rheumatol 2008;37:321-8.

53. Hashimoto J, Garnero P, van der Heijde D, Miyasaka N, Yamamoto $\mathrm{K}$, Kawai S, et al. A combination of biochemical markers of cartilage and bone turnover, radiographic damage and body mass index to predict the progression of joint destruction in patients with rheumatoid arthritis treated with disease-modifying anti-rheumatic drugs. Mod Rheumatol 2009;19:273-82.

54. Morgan SL, Anderson AM, Hood SM, Matthews PA, Lee JY, Alarcón GS. Nutrient intake patterns, body mass index, and vitamin levels in patients with rheumatoid arthritis. Arthritis Care Res 1997;10:9-17.

55. Liao KP, Weinblatt ME, Cui J, Iannaccone C, Chibnik LB, Lu B, et al. Clinical predictors of erosion-free status in rheumatoid arthritis: a prospective cohort study. Rheumatology 2011;50:1473-9.

56. Murray ML, Bergstresser PR, Adams-Huet B, Cohen JB. Relationship of psoriasis severity to obesity using same-gender siblings as controls for obesity. Clin Exp Dermatol 2009;34:140-4.

57. Bhole VM, Choi HK, Burns LC, Vera Kellet C, Lacaille DV, Gladman DD, et al. Differences in body mass index among individuals with PsA, psoriasis, RA and the general population. Rheumatology 2012;51:552-6.

58. Soltani-Arabshahi R, Wong B, Feng BJ, Goldgar DE, Duffin KC, Krueger GG. Obesity in early adulthood as a risk factor for psoriatic arthritis. Arch Dermatol 2010;146:721-6.

59. Herron MD, Hinckley M, Hoffman MS, Papenfuss J, Hansen CB, Callis KP, et al. Impact of obesity and smoking on psoriasis presentation and management. Arch Dermatol 2005;141:1527-34.

60. Huang YH, Yang LC, Hui RY, Chang YC, Yang YW, Yang CH, et al Relationships between obesity and the clinical severity of psoriasis in Taiwan. J Eur Acad Dermatol Venereol 2010;24:1035-9.

61. Driessen RJ, Boezeman JB, Van De Kerkhof PC, De Jong EM. Cardiovascular risk factors in high-need psoriasis patients and its implications for biological therapies. J Dermatolog Treat 2009;20:42-7.

62. Sakai R, Matsui S, Fukushima M, Yasuda H, Miyauchi H, Miyachi Y. Prognostic factor analysis for plaque psoriasis. Dermatology 2005;211:103-6.

63. Al-Mutairi N, Al-Farag S, Al-Mutairi A, Al-Shiltawy M. Comorbidities associated with psoriasis: an experience from the Middle East. J Dermatol 2010;37:146-55

64. Li W, Han J, Qureshi AA. Obesity and risk of incident psoriatic arthritis in US women. Ann Rheum Dis 2012;71:1267-72.

65. Ferraz-Amaro I, Arce-Franco M, Muñiz J, López-Fernández J, Hernández-Hernández V, Franco A, et al. Systemic blockade of TNF- $\alpha$ does not improve insulin resistance in humans. Horm Metab Res 2011;43:801-8.

66. Renzo LD, Saraceno R, Schipani C, Rizzo M, Bianchi A, Noce A, et al. Prospective assessment of body weight and body composition changes in patients with psoriasis receiving anti-TNF- $\alpha$ treatment. Dermatol Ther 2011;24:446-51.

67. Saraceno R, Schipani C, Mazzotta A, Esposito M, Di Renzo L, De Lorenzo A, et al. Effect of anti-tumor necrosis factor-alpha therapies on body mass index in patients with psoriasis. Pharmacol Res 2008;57:290-5

68. Prignano F, Ricceri F, Pescitelli L, Buggiani G, Troiano M, Zanieri F, et al. Comparison of body weight and clinical-parameter changes following the treatment of plaque psoriasis with biological therapies. Curr Med Res Opin 2009;25:2311-6.

69. Menter A, Gordon KB, Leonardi CL, Gu Y, Goldblum OM. Efficacy and safety of adalimumab across subgroups of patients with moderate to severe psoriasis. J Am Acad Dermatol 2010;63:448-56.

70. Lebwohl M, Yeilding N, Szapary P, Wang Y, Li S, Zhu Y, et al. Impact of weight on the efficacy and safety of ustekinumab in patients with moderate to severe psoriasis: rationale for dosing recommendations. J Am Acad Dermatol 2010;63:571-9.

71. Naldi L, Addis A, Chimenti S, Giannetti A, Picardo M, Tomino C, et al. Impact of body mass index and obesity on clinical response to systemic treatment for psoriasis. Evidence from the Psocare project. Dermatology 2008;217:365-73.

72. Papp KA, Langley RG, Lebwohl M, Krueger GG, Szapary P, Yeilding N, et al; PHOENIX 2 study investigators. Efficacy and safety of ustekinumab, a human interleukin-12/23 monoclonal antibody, in patients with psoriasis: 52-week results from a randomised, double-blind, placebo-controlled trial (PHOENIX 2). Lancet 2008;371:1675-84.

73. di Minno MN, Peluso R, Iervolino S, Lupoli R, Russolillo A, Scarpa $\mathrm{R}$, et al. Obesity and the prediction of minimal disease activity: a prospective study in psoriatic arthritis. Arthritis Care Res 2013;65:141-7

74. Xu Z, Vu T, Lee H, Hu C, Ling J, Yan H, et al. Population pharmacokinetics of golimumab, an anti-tumor necrosis factor-alpha human monoclonal antibody, in patients with psoriatic arthritis. J Clin Pharmacol 2009;49:1056-70.

75. Zhu Y, Hu C, Lu M, Liao S, Marini JC, Yohrling J, et al. Population pharmacokinetic modeling of ustekinumab, a human monoclonal antibody targeting IL-12/23p 40 , in patients with moderate to severe plaque psoriasis. J Clin Pharmacol 2009;49:162-75.

76. Gremese E, Carletto A, Padovan M, Atzeni F, Raffeiner B, Giardina 
AR, et al; Gruppo Italiano di Studio sulle Early Arthritis (GISEA). Obesity and reduction of the response rate to anti-tumor necrosis factor a in rheumatoid arthritis: an approach to a personalized medicine. Arthritis Care Res 2013;65:94-100.

77. Klaasen R, Wijbrandts CA, Gerlag DM, Tak PP. Body mass index and clinical response to infliximab in rheumatoid arthritis. Arthritis Rheum 2011;63:359-64.

78. Gisondi P, Del Giglio M, Di Francesco V, Zamboni M, Girolomoni G. Weight loss improves the response of obese patients with moderate-to-severe chronic plaque psoriasis to low-dose cyclosporine therapy: a randomized, controlled, investigator-blinded clinical trial. Am J Clin Nutr 2008;88:1242-7.

79. Hossler EW, Maroon MS, Mowad CM. Gastric bypass surgery improves psoriasis. J Am Acad Dermatol 2011;65:198-200.

80. Farias MM, Achurra P, Boza C, Vega A, de la Cruz C. Psoriasis following bariatric surgery: clinical evolution and impact on quality of life on 10 patients. Obes Surg 2012;22:877-80.

81. Smedslund G, Byfuglien MG, Olsen SU, Hagen KB. Effectiveness and safety of dietary interventions for rheumatoid arthritis: a systematic review of randomized controlled trials. J Am Diet Assoc 2010;110:727-35.

82. Grijalva CG, Chen L, Delzell E, Baddley JW, Beukelman T, Winthrop KL, et al. Initiation of tumor necrosis factor-a antagonists and the risk of hospitalization for infection in patients with autoimmune diseases. JAMA 2011;306:2331-9.

83. Wakkee M, de Vries E, van den Haak P, Nijsten T. Increased risk of infectious disease requiring hospitalization among patients with psoriasis: a population-based cohort. J Am Acad Dermatol 2011;65:1135-44.

84. Mease PJ, Ory P, Sharp JT, Ritchlin CT, Van den Bosch F, Wellborne F, et al. Adalimumab for long-term treatment of psoriatic arthritis: 2-year data from the Adalimumab Effectiveness in Psoriatic Arthritis Trial (ADEPT). Ann Rheum Dis 2009;68:702-9.

85. Burmester GR, Panaccione R, Gordon KB, McIlraith MJ, Lacerda AP. Adalimumab: long-term safety in 23458 patients from global clinical trials in rheumatoid arthritis, juvenile idiopathic arthritis, ankylosing spondylitis, psoriatic arthritis, psoriasis and Crohn's disease. Ann Rheum Dis 2013;72:517-24.

86. Lane MA, McDonald JR, Zeringue AL, Caplan L, Curtis JR, Ranganathan $\mathrm{P}$, et al. TNF-alpha antagonist use and risk of hospitalization for infection in a national cohort of veterans with rheumatoid arthritis. Medicine 2011;90:139-45.

87. Doran MF, Crowson CS, Pond GR, O'Fallon WM, Gabriel SE. Predictors of infection in rheumatoid arthritis. Arthritis Rheum 2002;46:2294-300.

88. Dommasch ED, Abuabara K, Shin DB, Nguyen J, Troxel AB, Gelfand JM. The risk of infection and malignancy with tumor necrosis factor antagonists in adults with psoriatic disease: a systematic review and meta-analysis of randomized controlled trials. J Am Acad Dermatol 2011;64:1035-50.

89. Strangfeld A, Hierse F, Rau R, Burmester GR, Krummel-Lorenz B, Demary W, et al. Risk of incident or recurrent malignancies among patients with rheumatoid arthritis exposed to biologic therapy in the German biologics register RABBIT. Arthritis Res Ther 2010;12:R5.

90. Dreyer L, Mellemkjaer L, Andersen AR, Bennett P, Poulsen UE, Juulsgaard Ellingsen T, et al. Incidences of overall and site specific cancers in $\mathrm{TNFa}$ inhibitor treated patients with rheumatoid arthritis and other arthritides - a follow-up study from the DANBIO Registry. Ann Rheum Dis 2013;72:79-82.

91. Chakravarty EF, Michaud K, Wolfe F. Skin cancer, rheumatoid arthritis, and tumor necrosis factor inhibitors. J Rheumatol 2005;32:2130-5.

92. Mariette X, Matucci-Cerinic M, Pavelka K, Taylor P, van Vollenhoven R, Heatley R, et al. Malignancies associated with tumour necrosis factor inhibitors in registries and prospective observational studies: a systematic review and meta-analysis. Ann Rheum Dis 2011;70:1895-904

93. Dixon WG, Watson KD, Lunt M, Mercer LK, Hyrich KL, Symmons DP; British Society For Rheumatology Biologics Register Control Centre Consortium; British Society for Rheumatology Biologics Register. Influence of anti-tumor necrosis factor therapy on cancer incidence in patients with rheumatoid arthritis who have had a prior malignancy: results from the British Society for Rheumatology Biologics Register. Arthritis Care Res 2010;62:755-63.

94. Mercer LK, Low AS, Galloway JB, Watson KD, Lunt M, Symmons DP, et al; BSRBR Control Centre Consortium. Anti-TNF therapy in women with rheumatoid arthritis with a history of carcinoma in situ of the cervix. Ann Rheum Dis 2013;72:143-4.

95. Hoff M, Bøyesen P, Haugeberg G, Vis M, Woolf AD, Havaardsholm EA, et al. High disease activity is a predictor of cortical hand bone loss in post-menopausal patients with established rheumatoid arthritis: a 5-year multicentre longitudinal study. Rheumatology 2010;49:1676-82.

96. Siu S, Haraoui B, Bissonnette R, Bessette L, Roubille C, Richer V, et al. Meta-analysis of tumor necrosis factor inhibitors and glucocorticoids on bone density in rheumatoid arthritis and ankylosing spondylitis trials. Arthritis Care Res 2015;67:754-64.

97. Laan RF, van Riel PL, van de Putte LB, van Erning LJ, van't Hof MA, Lemmens JA. Low-dose prednisone induces rapid reversible axial bone loss in patients with rheumatoid arthritis. A randomized, controlled study. Ann Intern Med 1993;119:963-8.

98. Hansen M, Podenphant J, Florescu A, Stoltenberg M, Borch A, Kluger E, et al. A randomised trial of differentiated prednisolone treatment in active rheumatoid arthritis. Clinical benefits and skeletal side effects. Ann Rheum Dis 1999;58:713-8.

99. Verhoeven AC, Boers M, te Koppele JM, van der Laan WH, Markusse HM, Geusens P, et al. Bone turnover, joint damage and bone mineral density in early rheumatoid arthritis treated with combination therapy including high-dose prednisolone. Rheumatology 2001;40:1231-7.

100. Güler-Yüksel M, Bijsterbosch J, Goekoop-Ruiterman YP, de Vries-Bouwstra JK, Hulsmans HM, de Beus WM, et al. Changes in bone mineral density in patients with recent onset, active rheumatoid arthritis. Ann Rheum Dis 2008;67:823-8.

101. Engvall IL, Svensson B, Tengstrand B, Brismar K, Hafström I; Better Anti-Rheumatic FarmacO Therapy Study Group. Impact of low-dose prednisolone on bone synthesis and resorption in early rheumatoid arthritis: experiences from a two-year randomized study. Arthritis Res Ther 2008;10:R128.

102. van Schaardenburg D, Valkema R, Dijkmans BA, Papapoulos S, Zwinderman AH, Han KH, et al. Prednisone treatment of elderly-onset rheumatoid arthritis. Disease activity and bone mass in comparison with chloroquine treatment. Arthritis Rheum 1995;38:334-42.

103. Choy EH, Kingsley GH, Khoshaba B, Pipitone N, Scott DL; Intramuscular Methylprednisolone Study Group. A two year randomised controlled trial of intramuscular depot steroids in patients with established rheumatoid arthritis who have shown an incomplete response to disease modifying antirheumatic drugs. Ann Rheum Dis 2005;64:1288-93.

104. Frediani B, Falsetti P, Bisogno S, Baldi F, Acciai C, Filippou G, et al. Effects of high dose methylprednisolone pulse therapy on bone mass and biochemical markers of bone metabolism in patients with active rheumatoid arthritis: a 12-month randomized prospective controlled study. J Rheumatol 2004;31:1083-7.

105. Wolfe F, Michaud K. Predicting depression in rheumatoid arthritis: the signal importance of pain extent and fatigue, and comorbidity. Arthritis Rheum 2009;61:667-73.

106. Melikoglu MA, Melikoglu M. The relationship between disease activity and depression in patients with Behcet disease and

Personal non-commercial use only. The Journal of Rheumatology Copyright @ 2015. All rights reserved. 
rheumatoid arthritis. Rheumatol Int 2010;30:941-6.

107. Ang DC, Choi H, Kroenke K, Wolfe F. Comorbid depression is an independent risk factor for mortality in patients with rheumatoid arthritis. J Rheumatol 2005;32:1013-9.

108. Papp K, Poulin Y, Vieira A, Shelton J, Poulin-Costello M. Disease characteristics in patients with and without psoriatic arthritis treated with etanercept. J Eur Acad Dermatol Venereol 2014;28:581-9.

109. Akay A, Pekcanlar A, Bozdag KE, Altintas L, Karaman A. Assessment of depression in subjects with psoriasis vulgaris and lichen planus. J Eur Acad Dermatol Venereol 2002;16:347-52.

110. Ak M, Haciomeroglu B, Turan Y, Lapsekili N, Doruk A, Bozkurt A, et al. Temperament and character properties of male psoriasis patients. J Health Psychol 2012;17:774-81.

111. Schneider G, Hockmann J, Stander S, Luger TA, Heuft G. Psychological factors in prurigo nodularis in comparison with psoriasis vulgaris: results of a case-control study. Br J Dermatol 2006;154:61-6

112. Murphy H, Dickens C, Creed F, Bernstein R. Depression, illness perception and coping in rheumatoid arthritis. J Psychosom Res 1999;46:155-64.

113. Hider SL, Tanveer W, Brownfield A, Mattey DL, Packham JC. Depression in RA patients treated with anti-TNF is common and under-recognized in the rheumatology clinic. Rheumatology 2009;48:1152-4.

114. Nas K, Sarac AJ, Gur A, Cevik R, Altay Z, Erdal A, et al. Psychological status is associated with health related quality of life in patients with rheumatoid arthritis. J Back Musculoskelet Rehabil 2011;24:95-100.

115. Kekow J, Moots R, Khandker R, Melin J, Freundlich B, Singh A. Improvements in patient-reported outcomes, symptoms of depression and anxiety, and their association with clinical remission among patients with moderate-to-severe active early rheumatoid arthritis. Rheumatology 2011;50:401-9.

116. Langley RG, Feldman SR, Han C, Schenkel B, Szapary P, Hsu MC, et al. Ustekinumab significantly improves symptoms of anxiety, depression, and skin-related quality of life in patients with moderate-to-severe psoriasis: Results from a randomized, double-blind, placebo-controlled phase III trial. J Am Acad Dermatol 2010;63:457-65.

117. Tyring S, Gottlieb A, Papp K, Gordon K, Leonardi C, Wang A, et al. Etanercept and clinical outcomes, fatigue, and depression in psoriasis: double-blind placebo-controlled randomised phase III trial. Lancet 2006;367:29-35.

118. Menter A, Augustin M, Signorovitch J, Yu AP, Wu EQ, Gupta SR, et al. The effect of adalimumab on reducing depression symptoms in patients with moderate to severe psoriasis: a randomized clinical trial. J Am Acad Dermatol 2010;62:812-8.

119. Fleming P, Roubille C, Richer V, Starnino T, McCourt C, McFarlane A, et al. Effect of biologics on depressive symptoms in patients with psoriasis: a systematic review. J Eur Acad Dermatol Venereol 2014;29:1063-70.

120. Krishnan R, Cella D, Leonardi C, Papp K, Gottlieb AB, Dunn M, et al. Effects of etanercept therapy on fatigue and symptoms of depression in subjects treated for moderate to severe plaque psoriasis for up to 96 weeks. Br J Dermatol 2007;157:1275-7.

121. Peters MJ, Symmons DP, McCarey D, Dijkmans BA, Nicola P, Kvien TK, et al. EULAR evidence-based recommendations for cardiovascular risk management in patients with rheumatoid arthritis and other forms of inflammatory arthritis. Ann Rheum Dis 2010;69:325-31.

122. Gossec L, Smolen JS, Gaujoux-Viala C, Ash Z, Marzo-Ortega H, van der Heijde D, et al; European League Against Rheumatism. European League Against Rheumatism recommendations for the management of psoriatic arthritis with pharmacological therapies. Ann Rheum Dis 2012;71:4-12.
123. Parsi KK, Brezinski EA, Lin TC, Li CS, Armstrong AW. Are patients with psoriasis being screened for cardiovascular risk factors? A study of screening practices and awareness among primary care physicians and cardiologists. J Am Acad Dermatol 2012;67:357-62.

124. Friedewald VE, Cather JC, Gelfand JM, Gordon KB, Gibbons GH, Grundy SM, et al. AJC editor's consensus: psoriasis and coronary artery disease. Am J Cardiol 2008;102:1631-43.

125. Smith CH, Anstey AV, Barker JN, Burden AD, Chalmers RJ, Chandler DA, et al; (Chair of Guideline Group). British Association of Dermatologists' guidelines for biologic interventions for psoriasis 2009. Br J Dermatol 2009;161:987-1019.

126. Coates LC, Tillett W, Chandler D, Helliwell PS, Korendowych E, Kyle S, et al; BSR Clinical Affairs Committee \& Standards, Audit and Guidelines Working Group and the BHPR. The 2012 BSR and BHPR guideline for the treatment of psoriatic arthritis with biologics. Rheumatology 2013;52:1754-7.

127. Singh JA, Furst DE, Bharat A, Curtis JR, Kavanaugh AF, Kremer JM, et al. 2012 update of the 2008 American College of Rheumatology recommendations for the use of disease-modifying antirheumatic drugs and biologic agents in the treatment of rheumatoid arthritis. Arthritis Care Res 2012;64:625-39.

128. Pereira IA, Mota LM, Cruz BA, Brenol CV, Fronza LS, Bertolo MB, et al; Brazilian Society of Rheumatology. 2012 Brazilian Society of Rheumatology Consensus on the management of comorbidities in patients with rheumatoid arthritis. Rev Bras Reumatol 2012;52:474-95.

129. Richard MA, Barnetche T, Horreau C, Brenaut E, Pouplard C, Aractingi S, et al. Psoriasis, cardiovascular events, cancer risk and alcohol use: evidence-based recommendations based on systematic review and expert opinion. J Eur Acad Dermatol Venereol 2013;27 Suppl 3:2-11

130. Wasko MC, Dasgupta A, Hubert H, Fries JF, Ward MM. Propensity-adjusted association of methotrexate with overall survival in rheumatoid arthritis. Arthritis Rheum 2013;65:334-42.

131. Westlake SL, Colebatch AN, Baird J, Kiely P, Quinn M, Choy E, et al. The effect of methotrexate on cardiovascular disease in patients with rheumatoid arthritis: a systematic literature review. Rheumatology 2010;49:295-307.

132. Micha R, Imamura F, Wyler von Ballmoos M, Solomon DH, Hernán MA, Ridker PM, et al. Systematic review and meta-analysis of methotrexate use and risk of cardiovascular disease. Am J Cardiol 2011;108:1362-70

133. Westlake SL, Colebatch AN, Baird J, Curzen N, Kiely P, Quinn M, et al. Tumour necrosis factor antagonists and the risk of cardiovascular disease in patients with rheumatoid arthritis: a systematic literature review. Rheumatology 2011;50:518-31.

134. Barnabe C, Martin BJ, Ghali WA. Systematic review and meta-analysis: anti-tumor necrosis factor a therapy and cardiovascular events in rheumatoid arthritis. Arthritis Care Res 2011;63:522-9.

135. Zhang C, Rexrode KM, van Dam RM, Li TY, Hu FB. Abdominal obesity and the risk of all-cause, cardiovascular, and cancer mortality: sixteen years of follow-up in US women. Circulation 2008;117:1658-67.

136. Pischon T, Boeing H, Hoffmann K, Bergmann M, Schulze MB, Overvad K, et al. General and abdominal adiposity and risk of death in Europe. N Engl J Med 2008;359:2105-20.

137. Solomon DH, Peters MJ, Nurmohamed MT, Dixon W. Unresolved questions in rheumatology: motion for debate: the data support evidence-based management recommendations for cardiovascular disease in rheumatoid arthritis. Arthritis Rheum 2013;65:1675-83. 